\title{
Work in Progress: Understanding Student Successes, Challenges, and Per- ceptions of Community
}

\section{Dr. Deepak R. Keshwani, University of Nebraska, Lincoln}

Dr. Deepak Keshwani is an associate professor of Biological Systems Engineering at the University of Nebraska-Lincoln. In addition to research in the area of bioprocess and biosystems modeling, Dr. Keshwani is engaged in teaching and advising students across two academic colleges and is involved in numerous campus-wide student success initiatives including leading a civic-engagement program for first-year students.

\section{Dr. Jennifer Keshwani, University of Nebraska, Lincoln}

Jenny Keshwani is an Assistant Professor of Biological Systems Engineering and Science Literacy Specialist in the Institute of Agriculture and Natural Resources at the University of Nebraska-Lincoln. She is active in promoting science and engineering education in both formal and informal settings through her research, extension, and outreach activities. Dr. Keshwani is actively engaged in several cross-disciplinary regional and national efforts related to STEM education and outreach. Most recently, she was part of a team that received NSF funding to engage youth in STEM through wearable technologies. 


\title{
Understanding student successes, challenges, and perceptions of community: Work-in-Progress
}

\begin{abstract}
The Biological Systems Engineering department at the University of Nebraska-Lincoln (UNL) has two undergraduate programs in engineering (agricultural engineering and biological systems engineering), and one undergraduate program in mechanized systems management which is an agricultural systems management/technology (ASMT) program. The overall goal of this study is to understand student perception of community in the context of the department's academic programs, and identify strategies to build community among ASMT students to positively impact student retention and student success in team-based learning environments. Sophomores in the ASMT program enrolled in a required problem solving and technical communication course taught by the department during the Spring 2018 semester were the focus of this study. During the course of the semester, students were asked to complete short qualitative survey questions related to successes and challenges encountered as students, and their perceptions of community. Broadly defined questions were selected for this study to avoid biasing of responses. Institutional Review Board approval was obtained for the study. There were 25 students enrolled in the class and 16 students provided consent to be included in this study. The data analysis procedure followed is based on the model of thematic analysis which starts by identifying conceptual thematic codes through review of responses for each question. Results indicate that ASMT students have some similarities with their engineering counterparts, but place a stronger focus on relationships and building connections. Students valued the use of group projects as a way to build community and noted the importance of classroom management to build community.
\end{abstract}

\section{Introduction}

Across the country, many biological and agricultural engineering departments are also home to agricultural systems management/technology (ASMT) programs. From a historical perspective, nearly all these ASMT programs have evolved from traditional agricultural mechanization programs. This evolution parallels how biological engineering programs evolved from traditional agricultural engineering programs. We know anecdotally at our institution that student populations pursuing ASMT programs are distinctly different from those pursuing engineering programs in terms of performance on college entrance assessments (ACT, SAT etc.). The majority of faculty who teach ASMT programs have engineering degrees, which could limit their ability to anticipate ASMT student challenges. Faculty can be more effective in their teaching, advising and mentoring if they understand clearly the specific challenges of their students. There have been no prior published work related to success of students pursuing ASMT programs, although there has been some work in related topics for agricultural/biological engineering students: a study assessing motivation to pursue their majors [1], a study comparing curriculum of various agricultural and biological engineering programs [2], and finally a study that presented challenges and successes reported by sophomore agricultural and biological engineering students [3].

The overall goal of our work is to understand student perception of community in the context of the department's academic programs, and identify strategies to build community among students to positively impact student retention and student success in team-based learning environments. 
In the context of our department, past efforts to improve student success in the ASMT program have primarily focused on the first-semester orientation class that has a heavy emphasis on student success activities. This has resulted in consistent first-year retention rates of over $95 \%$ over the last five years. However, with the significant number of students transferring into the program, we were interested in assessing student perceptions of community in the program. While our retention rates are high, we also were interested in probing student self-reported challenges during the first-year to guide future changes in our first-year class. A logical class to survey was a sophomore level problem solving and technical communication class that is required for all students, including those who join the program after the first semester. For this preliminary work, we utilized a qualitative survey to capture open ended responses from students on questions related to community building, challenges encountered, and self-reported success.

\section{Methods}

The focus of this study were ASMT students enrolled in a sophomore level course focused on problem solving and technical communication required only for students in the major. There were 25 students enrolled in the class. Prior to the start of the semester, we received IRB approval (\# 20170917402EX) to conduct the research. At the start of the semester, a co-author of the study not affiliated with the class collected the informed consent forms which were stored in a sealed envelope and provided to the instructor at the end of the semester. During the course of the semester, students were asked to complete short qualitative survey questions related to successes and challenges encountered as students, and their perceptions of community. Questions were embedded into required assignments for all students and were submitted online through our learning management system. Broadly defined questions were selected for this study to avoid biasing of responses. There were 25 students enrolled in the class and 16 students provided consent to be included in this study. The response rate of $64 \%$ is consistent with similar studies done in our program. We acknowledge that results could be biased based on the motivations of students in their decision to participate. The data analysis procedure followed is based on the model of thematic analysis which starts by identifying conceptual thematic codes through review of responses for each question and is based on methodology described by Braum and Clarke [4]. A list of questions posed to the students is shown in Table 1.

Table 1. Open-ended response questions embedded in student assignments

\begin{tabular}{|l|l|}
\hline Category & Questions \\
\hline Challenges \& & $\begin{array}{l}\text { 1. What was your biggest challenge during your First-Year at } \\
\text { UNL? }\end{array}$ \\
$\begin{array}{l}\text { 2. What was your greatest success during your First-Year at UNL? } \\
\text { 3. Thinking back to some of the challenges you faced during your } \\
\text { first year at UNL, list one or two specific things that you have } \\
\text { done differently as a sophomore. }\end{array}$ \\
\hline Perceptions & $\begin{array}{l}\text { What does community mean to you? What specific activity } \\
\text { would you suggest implementing to build community in a } \\
\text { classroom? } \\
\text { Describe the community we've built in this class over the } \\
\text { semester. What specific activities helped or hindered the } \\
\text { development of community within our class? }\end{array}$ \\
\hline
\end{tabular}




\section{Results and Discussion}

\section{Challenges and Successes:}

Student successes and challenges were coded into ten categories previously defined in a study on student success and challenges of agricultural and biological engineering students [3]. The success and challenge codes included: Extracurriculars, Teams, Interpersonal Relationships, Change Major/Career Path, Motivation, Study Skills, Acclimating, Time Management, Life Balance, Academics, and Learning. Student responses were most often coded as Interpersonal Relationships (67\% of responses) as their greatest success and Acclimating (38\%) as their biggest challenge (Figure 1).

Most student successes coded as Relationships reflected building community with their peers as a success. For example, one student commented

'I consider my greatest success for my first year, which was this year, was all of the different people I have met, and the connections made whether it's been the classmates in my [ASMT] classes or the friends I made from joining Alpha Gamma Rho. Coming here from California not knowing anyone was pretty intimidating at first but I'm extremely happy with the community here at UNL as a whole and how I've been treated since I moved out here.'

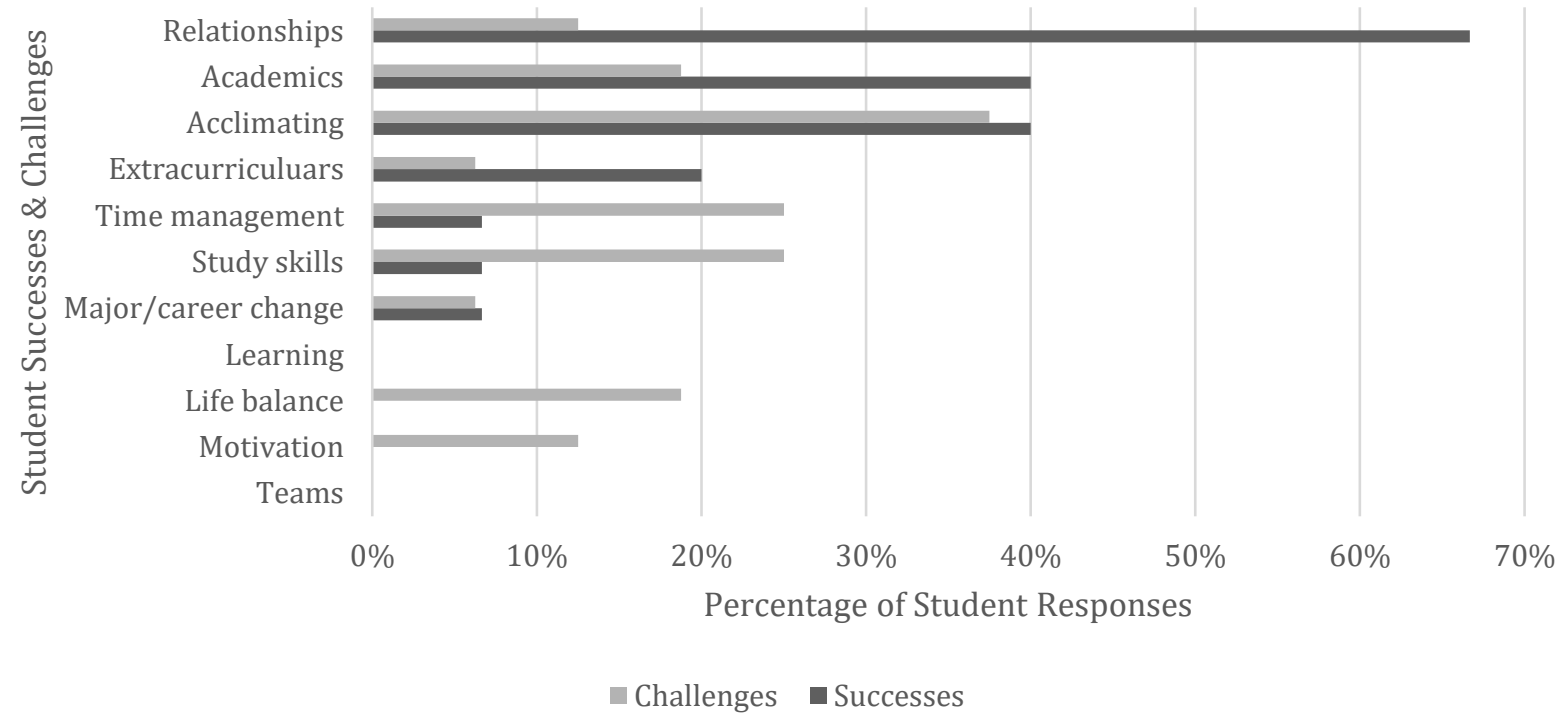

Figure 1: Frequency of thematic codes in reported student challenges and successes while pursuing a degree in ASMT.

Many students focused on Acclimating to the university or a new town as their greatest successes and their greatest challenge. This is to be expected as majority of students in the ASMT program are from small rural communities. In the responses, students reflected both on the academic and non-academic aspects of acclimation. These sentiments were evident in following responses: 
'Coming from Western Nebraska in a small town of 800 people it's a huge adjustment to come way out here and feel at home. By getting through it I mean that I made connections, friends and completed my classes. I worked hard and did it for the most part.'

'My biggest challenge in my first year was adapting to the college learning style. Coming from a class of 19 to having classes with well over 100 people made it difficult to learn right away. My first semester tests didn't go very well due to this. It took me a while to figure out how to study for tests.'

'The biggest challenge of my first year was adjusting to the city life. Before coming to college, I had never driven in Lincoln or a city for that matter, I'd have to say that the one ways got me the most. Learning the layout of Lincoln took some time also for the first few months I had use google maps almost everywhere I went. City campus took me a while to map out also, it took me an hour to find out where I was supposed to pay my tuition at. Also learning how the university works and what I can and can't do verses high school was another challenge.'

Time Management and Study Skills were also identified as challenges for students and very few reported those among their success. For example, students commented:

'My biggest challenges during my first-year at UNL would have to be arranging priorities, managing my time wisely, and not getting burnt out half way through the semester.

'My greatest challenge during my first year at UNL was trying to manage my free time effectively, while also trying to have fun.'

Responses from ASMT students were compared to a prior study that examined Agricultural Engineering (AE) and Biological Systems Engineering (BE) students in the same department [3]. We had access to the raw data from that study. Our comparison revealed that ASMT students were more likely to report relationships as a success than engineering students. (67\% ASMT $13 \% \mathrm{BE} ; 0 \% \mathrm{AE})$. ASMT students were similar to AE students in identifying acclimation and study skills as a challenge. ASMT students were more likely to report Time Management as a concern (25\%) similar to the BE students while AE focused more on Life Balance (27\%). We anticipated more similarities between ASMT and AE students.

Students were also asked to identify tactics for success that they used as sophomores to overcome challenge (data not shown in paper). Time Management skills was the most common success tactic and students tended to talk a lot about dealing with procrastination as evident in the following responses:

'Procrastination is something that I have worked on immensely. I now usually start working a homework soon after it assigned instead of right before it is due. I try to plan ahead more often also so I can do things I want instead of writing a paper or something while my friends are out having fun.' 
'One thing I have done differently is try to limit my procrastination. A couple years ago I probably would have tried to cram this assignment in last minute, but now I'm completing it on Monday! Another improvement I have made is using a planner, so I make sure I have time to complete all assignments and study for tests.

The idea of relationships and connections shows up as a distinct difference between ASMT students and their engineering counterparts, which needs further investigation. Students were passionate about connecting with others as a strategy to overcome challenges. Student comments included the following:

'My first year I was in all of my classes with strangers that I didn't really know and had to figure out the class alone. This year I am in many classes with people that I know, it is easier to better understand the material.'

'As a sophomore, I focused on being social and finding that happy medium between school and my social life. I got involved on campus with the Nebraska Human Resources Institute mentoring a 7th grade student that attends Lux middle school. This has been one of my more life changing, motivational, positive, and leadership building opportunities that anyone could have.'

\section{Community perceptions:}

Students were asked to describe community in general at the beginning of the course and then asked to describe the community that had been built within their class at the end of the semester. Student definitions were coded into five categories (Figure 2).

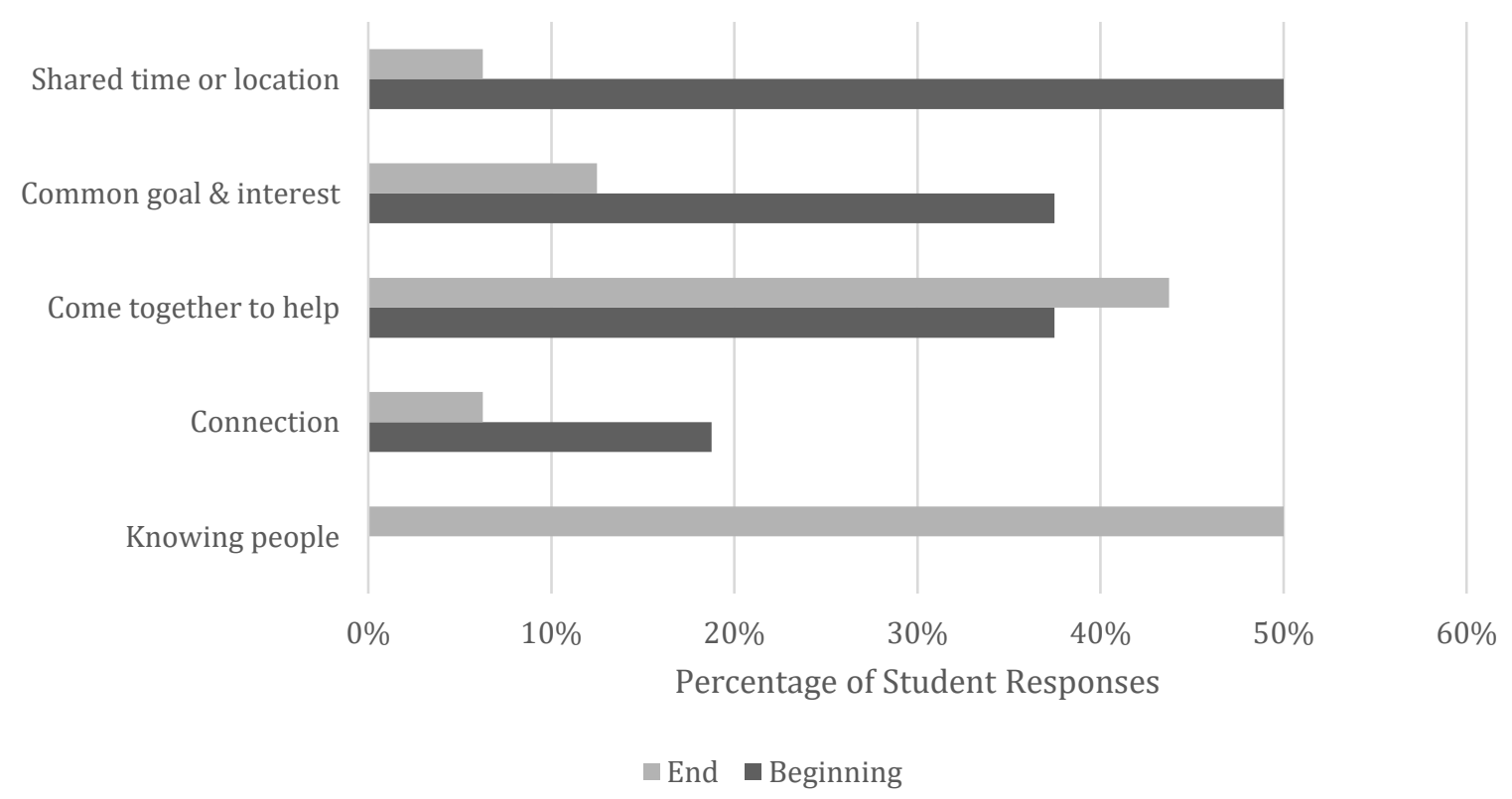

Figure 2: Frequency of thematic codes for student responses to defining community at the beginning and end of the semester. 
The community definition codes included: Shared time or location, Common goal \& interest, Come together to help, Connection, and Knowing people. The most common response at the beginning of the semester was that community has a Shared Time or Location $(50 \%)$ which was closely followed by having a Common Goal \& Interest (38\%) and Coming Together to Help $(38 \%)$.

Student responses at the beginning of the semester highlighted the idea that communities share Time and Location. A sample response included,

'Community means a group of people around each other. In a classroom I see the community as all students from around the country gathering and studying the same subject.'

Often students combined having a Shared Time or Location with other aspects of defining a community. For example:

'Community is a group of people who share a similar environment, such as a town, college classes, major, or club who all have the same interest in mind and are willing to give back to those around them in order ensure success.'

'Community in my mind is a group of individuals that share similar or different interests that come together behind a cause or are looking to accomplish a certain goal. Also, I would further define community as the environment that surrounds you in day to day dealings, such as our 262 class.'

At the end of the semester, the focus of student responses had shifted as seen by the dramatic increase in responses that defined community as simply Knowing People. This was apparent in several responses such as:

'For me I know roughly half of the people within our community and would feel comfortable talking to them and asking for help for example.'

'Just class builds that community feeling, because students have the opportunities to meet and interact with new people.'

Students were asked at the beginning of the semester to identify activities that could be used to encourage the development of community within their class. Similarly, at the end of the semester, students were asked to comment on the class activities that they saw as beneficial to developing community within their class (Figure 3). Responses were coded into four areas, including: Group projects, Classroom management, Self-motived efforts, and Evolves naturally (the idea that just being together is sufficient to build community). 


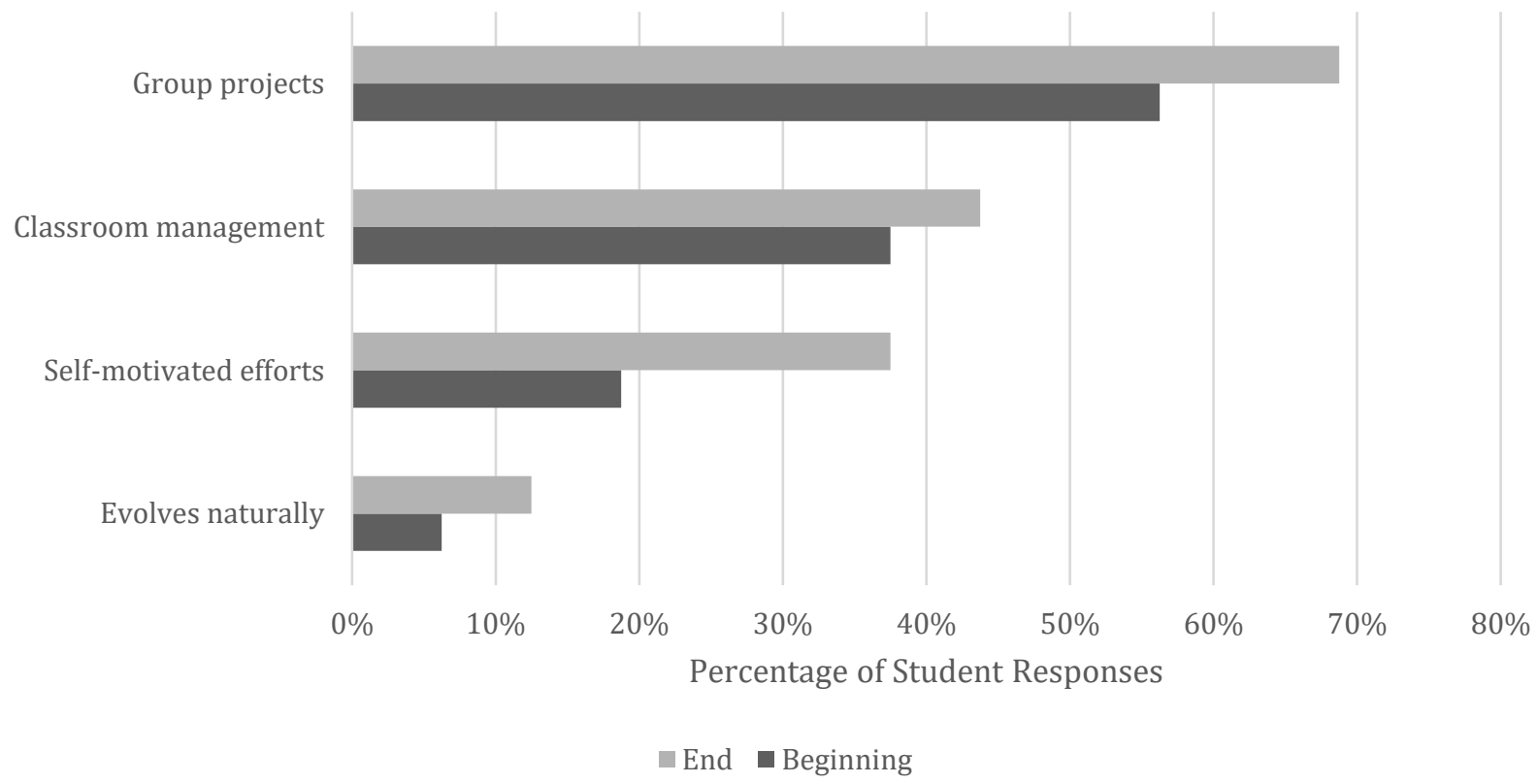

Figure 3: Frequency of thematic codes for student suggestions for how to develop a sense of community within the classroom.

The most common response indicated that Group Projects help develop community amongst students (Beginning 56\%; End 69\%). The following student comments describe the effect of group projects on community at the beginning of the semester.

'In order to build a community in the setting of a class room group work is key. It is key because groups must come together in order to get things accomplished. Teams get work done in a fast and efficient manner plus they are an excellent way to develop connections and relationships that will be beneficial for one's future career.'

'One specific activity I would suggest is getting people involved weekly or bimonthly in different groups to accomplish tasks. Such as lab work groups or group projects.'

There was not much change in student responses for how to develop community between the beginning and end of the semester. Students continued to identify group projects as a key part of building community within a class.

'I think the group project definitely helped with the building of our classroom community.'

'At the beginning of the semester all of the students were individuals alone. The community started to come together when we were assigned a group project. That group for the project was comprised of 4 people so our community was a community of 4.'

Classroom management styles were also identified as a way to develop community within the class. Student comments at the beginning of the semester included: 
'I think the main thing would be meeting for class more frequently would help or at all possible allow more class conversation.'

'By bringing students' desks together, or putting them into groups, it causes them to work together and create a community environment.'

These thoughts were echoed at the end of the semester. Students commented:

'...during the lectures when we'd pause and discuss things or do a little activity I believe that helps to get everybody involved and talking with one another.'

'One thing that these small [ASMT] classes have is a relaxed learning environment, where most people know each other and get along really well. We all are here to learn and we can work together to problem solve.'

It appears that students really value group or team-based activities and have a desire to have more opportunities to interact with each other during the class. The ASMT program in our department has historically had a heavy emphasis on laboratory activities that are primarily team-based. However, in recent years, there has been an increase in the use of team-based activities during lecture sessions as well.

\section{Conclusions}

This work-in-progress study reveals that ASMT have some similarities with their engineering counterparts after our results were compared to those of $\mathrm{AE}$ and $\mathrm{BE}$ students in a previously reported study. However, a stronger focus on relationships and building connections with others was observed for ASMT students. Students valued the use of group projects as a way to build community, and reinforced the idea that classroom management (i.e. facilitating interactions, discussion activities) helps build communities. At the start of the semester, students defined community in the context of shared time, and location, but at the end of the semester, their perceptions of community had more to do with knowing each other.

In our academic unit, we have long approached teaching, advising and mentoring assuming that ASMT and AE students as having a lot of similarities and viewed them collectively being different than BE students. Our results seem to indicate that our ASMT population appears to be distinct and share some similarities with both AE and BE students. Although, since the sample sizes are small, this needs to be further explored.

At this point, our qualitative survey has revealed some themes that we plan to use in several ways. We will share the data with faculty and advisers in our programs to support their teaching, advising, and student mentoring efforts. We anticipate that the results from this paper will be used to guide future discussions on student success initiatives in the department. We recognize the small sample size of students is a limiting factor in our study. However, we plan to use the themes that emerged from this work to design a systematic mixed-methods study to survey a larger sample of students in departments similar to ours to expand the scope of the study. 


\section{References}

1. Keshwani, J. \& Curtis, E. "To Change the World: Student Motivation for Pursuing a Degree in Agricultural or Biological Engineering". Paper presented at 2017 ASEE Annual Conference \& Exposition, Columbus, Ohio. https://peer.asee.org/29031

2. Kaleita, A L., \& Raman, D. R., A Rose by Any Other Name: An Analysis of Agricultural and Biological Engineering Undergraduate Curricula.. Transactions of the ASABE, pp. 2371-2378, 2012

3. Keshwani, J., Keshwani, D.K., \& Curtis, E. "Student Identification of Challenges and Successes in Agricultural and Biological Engineering." In Proceedings of the ASABE 2017 Annual International Meeting, Spokane, WA, July 2017.

4. Braun, V. \& Clarke, V., Using thematic analysis in psychology. Qual. Res. Psych., 3(2), 77-101., 2006 